\title{
Pregnancy, prescription medicines and the potential risk of herb-drug interactions: a cross-sectional survey
}

\author{
James S. McLay ${ }^{1 *}$, Naila Izzati ${ }^{1}$, Abdul R. Pallivalapila², Ashalatha Shetty ${ }^{3}$, Binita Pande ${ }^{4}$, Craig Rore $^{5}$,
} Moza Al Hail ${ }^{2}$ and Derek Stewart ${ }^{6}$

\begin{abstract}
Background: Pregnant women are routinely prescribed medicines while self-medicating with herbal natural products to treat predominantly pregnancy related conditions. The aim of this study was to assess the potential for herb-drug interactions (HDIs) in pregnant women and to explore possible herb-drug interactions and their potential clinical significance.

Methods: A cross-sectional survey of women during early pregnancy or immediately postpartum in NorthEast Scotland. Outcome measures included; Prescription medicines use excluding vitamins and potential HDls assessed using Natural Medicines Comprehensive Database.

Results: The survey was completed by 889 respondents (73\% response rate). 45.3\% (403) reported the use of at least one prescription medicine, excluding vitamins. Of those taking prescription medicines, $44.9 \%$ (181) also reported concurrent use of at least one HNP (Range 1-12). A total of 91 different prescription medicines were reported by respondents using HNPs. Of those taking prescription medicines, 44.9\% (181) also reported concurrent use of at least one HNP (Range 1-12). Thirty-four herb-drug interactions were identified in 23 (12.7\%) women with the potential to increase the risk of postpartum haemorrhage, alter maternal haemodynamics, and enhance maternal/fetal CNS depression.

Almost all were rated as moderate (93.9\%), one as a potentially major (ginger and nifedipine) and only one minor (ondansetron and chamomile).

Conclusion: Almost half of pregnant women in this study were prescribed medicines excluding vitamins and minerals and almost half of these used HNPs. Potential moderate to severe HDls were identified in an eighth of the study cohort. Healthcare professionals should be aware that the concurrent use of HNPs and prescription medicines during pregnancy is common and carries potential risks.
\end{abstract}

Keywords: Herbal, Botanical, Pregnancy, Herb-drug interaction, Antenatal, Postnatal, Female, Surveys and questionnaires

\section{Background}

Complementary and alternative medicine (CAM) use is reportedly increasing worldwide, with data from the United Kingdom (UK), Europe and United States (USA) confirming that herbal and natural products (HNP) are the most frequently used form of CAM therapy [1-5]. Although HNP have been used widely for thousands of years there is a lack of robust data to support their medical

\footnotetext{
* Correspondence: j.mclay@abdn.ac.uk

${ }^{1}$ The Division of Applied Health Sciences, The University of Aberdeen,

Aberdeen, UK

Full list of author information is available at the end of the article
}

use. Despite the lack of safety and efficacy data the public do not appear to be deterred from using them with 5.9\%$48.3 \%$ of Europeans and $12-18 \%$ of North Americans reportedly using HNP $[4,5]$. Herbal medicines are often promoted as harmless and users typically cite that HNPs provide a safe alternatives to pharmaceutical medicines, as a reason for use [6]. However the use of HNP has been associated with adverse effects due to direct chemical toxicity, herb-drug and herb-herb interactions, incorrect dosing, toxic constituents (renal or hepatic toxins), and product adulteration or contamination with toxic metals, microbes, or pollutants [7-18]. 
Women are recognised to be the major users of HNP for treatment of disease and maintenance of health $[3-5,19,20]$, and this widespread use also extends into pregnancy, where reportedly between 10 and $74 \%$ of pregnant women in Australia, Europe, UK and the USA use these products [21-30]. Recent data suggest that approximately $40 \%$ of UK pregnant women use HNP to treat pregnancy related problems such as nausea and vomiting or as nutritional supplements to aid fetal development [26, 27].

Although the potential risks associated with the use of prescription medicines during pregnancy are well recognised, data from Australia, Europe and North and South America, suggest that $12-81 \%$ of pregnant women are prescribed medicines by their healthcare professional who may be unaware of possible HNP use by their patient [31-35]. Therefore, during pregnancy many women may be using both HNP and prescribed medicines resulting in a risk of an herb-drug interaction which may be significant $[36,37]$. The current level of concomitant HNP and prescription medicine use in the UK is unclear, studies from North America, Europe, Asia and Africa suggest that between $2.5 \%-13 \%$ of pregnant women use herbal and natural products together with prescribed medicines [38-41]. Currently, there are limited published data from the UK reporting the levels of HNP use together with prescription medicines during pregnancy and the possible resultant herb-drug interactions.

The aims of this study were to assess the prevalence and characteristics of HNP use in pregnant women also taking prescription medicines and to explore the possible herb-drug interactions and their potential clinical significance.

\section{What is known about this subject}

- Women are recognised to be the major users of HNP, for treatment of disease and maintenance of health, and in high, middle and low income countries this widespread use also extends into pregnancy.

- Given that $12-81 \%$ of pregnant women use prescription medicines, a significant number are likely to also be using HNP with the risk of potential herb-drug interactions.

\section{What this study adds}

- Almost half of all pregnant women in our study population are prescribed medicines and almost half of these use HNPs.

- The potential for moderate to severe herb-drug interactions were identified in an eighth of women.

\section{Methods}

Data assessing the use of CAM collected from women attending for their mid-trimester (18-21 weeks) scan $(n=332)$ and women, within the first $24 \mathrm{~h}$ following a live birth, admitted to the postnatal unit $(n=557)$ at the Royal Aberdeen Maternity Hospital, North-East Scotland were combined. Data collection was completed in 2012 and study methods have been reported in detail elsewhere [26, 27]; brief study details are given for completeness. Questionnaires based on the findings of a systematic review assessing the quality of relevant study methodologies [6] were given to women attending the antenatal clinic for their mid trimester scan or on the postnatal ward following delivery. The questionnaire was written in English only and tested for face and content validity by a panel of healthcare professionals, pregnant and postpartum women. The final questionnaire contained four sections comprising: health and medication use during pregnancy (4 items); personal use of CAM therapies (7 items, extensive checklist of CAM modalities and products); attitudes toward CAM use during pregnancy (6 items); and demographics (5 items). Questions were a mix of closed and Likert statements. As the questionnaire was anonymous no reminders were issued. To optimise the return rate the questionnaire did not seek information on the quantity, timing, dose or duration of herb and food supplements taken. From the combined study populations all women reporting the use of prescribed medicines and/or herbal or natural products were identified. To help participants to identify correctly the products or modalities considered as herbal or natural products a check list was provided listing 40 herbal and natural products from the Medicines and HealthcareProducts Regulatory Agency with space for other products which the respondent might be using. Prescribed medicines were recorded by asking the respondent "Have you taken any prescribed medicines during this pregnancy? If yes, please write the names of all the medicines you have been prescribed."

\section{Statistical analysis}

Data were coded and entered into an SPSS 22.0 database. Descriptive statistics were used to analyse the data and provide respondent profile. Chi-square was used to test the associations between age, education and the use of herbal or natural products; $p<0.05$ was considered statistically significant.

\section{Herb-drug interaction analysis}

The potential for herbal and natural product interaction with prescribed medicines was assessed using the Natural Medicines Comprehensive Database [42]. This database reports and grades known interactions as major (do not use combination; contraindicated; strongly discourage patients 
from using this combination; a serious adverse outcome could occur), moderate (use cautiously or avoid combination; warn patients that a significant interaction or adverse outcome could occur), and minor (be aware that there is a chance of an interaction; advise patients to watch for warning signs of a potential interaction) together with a description of the mechanism underlying the interaction.

\section{Ethics statement}

This research was approved by National Health Service North of Scotland Research Ethics Committee and National Health Service Grampian Research and Development Committee on June 27, 2011 (REC 11/AL/0094). As the Ethics Committee required the survey questionnaires to be fully anonymous and returned directly by respondents in post-paid envelopes with no record of identifiable data, written consent to participate was deemed unnecessary.

\section{Results}

A total of 889 respondents completed the questionnaire on herbal and natural products use (332 antenatal, 557 immediate postnatal, response rates $66 \%$ and $80 \%$ respectively, study period March-August 2012). Of the 889 respondents, $45.3 \%$ (403) reported the use of at least one prescription medicine, excluding vitamins and minerals. Of the 403 pregnant women reporting the use of prescription medicines, $44.9 \%$ (181) also reported the concurrent use of at least one herbal or natural product (Range 112 ), equating to $20.4 \%$ of the total study population.

The demographics of women reporting concurrent use of HNP and prescription medicines ("Users") and those reporting prescription medicines only ("Non-Users") are reported in Table 1 . "Users" were significantly older $(p<$ $0.05)$ and had a higher education status $(p<0.05)$ than "non-users". "Users" in the early pregnancy group reported the use of 16 different herbal and natural products, of which ginger was the most commonly cited (35.6\%), followed by chamomile (23.2\%), cranberry $(20.5 \%)$, and fish oil $(12,3 \%)$. In the late pregnancy group, a total of 20 herbal and natural products were reported, of which raspberry was most frequently used (42.5\%) followed by cranberry $(26.7 \%)$, ginger $(23.7 \%)$, fish oil $(14.8 \%)$, and chamomile $(11.8 \%)$. The majority of "users" (57.1\%) reported the use of one HNP, 20.1\% two, 15.8\% three and 7.0\% four or more HNPs (Range 1-6).

\section{Prescription medicine use by "users"}

The use of a single prescription medicine was reported by over half (54\%) of "users", two medicines by $26 \%$, three by $10 \%$, four by $5 \%$ and five or more by $5 \%$ (range 1-12). A total of 91 different prescription medicines were reported by respondents, the top drug groups in order of frequency were: antibacterials (18.3\%); opiate analgesics (8.3\%); anti-emetics (7.1\%); thyroid replacement
Table 1 Demographics of women reporting concurrent use of prescription medicines with herbal and natural products (Users) and women reporting prescription medicine use only (Non-Users) $(n=403)$

\begin{tabular}{|c|c|c|c|}
\hline & $\begin{array}{l}\text { "Users" } \\
(n=174, n(\%))\end{array}$ & $\begin{array}{l}\text { "Non-Users" } \\
(n=229, n(\%))\end{array}$ & $\begin{array}{l}p \text {-value } \\
\text { (Chi-square) }\end{array}$ \\
\hline \multicolumn{4}{|l|}{ Age (years) } \\
\hline $15-24$ & $20(11.5)$ & $35(15.3)$ & \\
\hline $25-34$ & $101(58)$ & $149(65)$ & \\
\hline$\geq 35$ & $53(30.4)$ & $45(19.7)$ & $<0.05$ \\
\hline \multicolumn{4}{|l|}{ Education level } \\
\hline University & $99(56.9)$ & $108(47.2)$ & \\
\hline College & $52(29.8)$ & $63(27.5)$ & \\
\hline Secondary school & $23(13.2)$ & $56(24.4)$ & $<0.05$ \\
\hline Not stated & & $2(0.8)$ & \\
\hline \multicolumn{4}{|c|}{ Number of prescribed medicines } \\
\hline Median (IQR) & $1(1-2)$ & $1(1-2)$ & \\
\hline Range & $1-12$ & $1-10$ & \\
\hline \multicolumn{4}{|c|}{ Number of herbal/natural products } \\
\hline Median (IQR) & $1(1-2)$ & & \\
\hline Range & $1-6$ & & \\
\hline
\end{tabular}

(7.1\%); non-steroidal anti-inflammatory drugs (NSAIDs) and aspirin (6.6\%); laxatives (6.6\%); antacids (5.8\%), beta2 -agonists (5\%); non-opiate analgesics (paracetamol) 4.6\%, $\mathrm{H} 2$ antagonists (4.1\%); and antidepressants (4.1\%).

The majority of respondents (56.9\%) reported the use of one HNP with prescribed medicines, $20 \%$ reported two, $16 \%$ three, $5 \%$ four and $2 \%$ five or more (range $1-6$ ).

\section{Potential herbal and natural products-prescription medicine interactions}

Eight distinct HNP entities were identified as having the potential to cause interactions with concurrent prescription medicines. These were aloe, chamomile, cranberry, fish oil, ginger, ginseng, grapefruit, and sage. A total of 34 potential herb-drug interactions were identified in 23 (12.7\%) of the "users". Of the 34 potential interactions, almost all were rated as moderate $(93.9 \%)$, one as a potentially major (ginger and nifedipine) and only one minor (ondansetron and chamomile). Two underlying mechanisms for the potential interactions were pharmacodynamic, accounting for $54.5 \%$ and pharmacokinetic via inhibition of cytochrome P450 enzymes or decreased drug absorption, the remainder.

The prescribed drug classes with the potential for interaction with HNP were antithrombotic agents (7), antihypertensive agents (6), antidiabetic agents (5), hypnotics and anxiolytics (4), opiate analgesics (4), NSAIDs (3), hormonal therapies (2, prevention of miscarriage), proton pump inhibitors (1), insulin (1) and anti-emetics (1). The HNP and interacting prescription medicines 
together with the potential severity and mechanism of the interaction are reported in Table 2.

\section{Discussion}

Almost half of our study population were taking prescription medicines and just under half of these reported the concurrent use of at least one herbal or natural product. We identified potential herb-drug interactions in an eighth of women who concurrently used both HNP and prescription medicines, with one interaction being reported as potentially severe, one as mild and the remainder as moderate in severity.

Herbal medicines are the most common form of CAM used worldwide [43] with women reportedly the main users [20]. Despite the lack of robust safety and efficacy data for HNPs, recent studies suggest that approximately $40 \%$ of pregnant women in the UK report herbal and natural product use during early and or late pregnancy $[26,27]$. In this study we identified that almost half of pregnant women were using prescription medicines, which is in agreement with the findings of previous studies reporting that $12-81 \%$ of pregnant women use prescription medicines [31-35].

Although the current level of concomitant HNP and prescription medicine use in the UK is unclear, studies from North America, Sweden, Kenya and Iran suggest that between $2.5 \%-13 \%$ of pregnant women use HNP together with prescribed medicines [38-42]. The levels of HNP and prescribed medicines use reported in the published literature are highly variable and generally lower than those observed in our study; however, there are significant methodological differences in the manner in which data was collected from these different study populations, which make direct comparison difficult [44].

In this study we identified 34 potential HNP-drug interactions, predominantly classified as moderate with one mild and one severe, affecting 12.7\% of HNP users. This would suggest that approximately 1 in 20 of all pregnant women in the UK, who use HNP, are at risk from a potential herb-drug interaction. While the potential for herb-drug interactions has been assessed in patients with a variety of disease states, only one study has reported on the prevalence and severity of such interactions in the pregnant population [38]. Moussally et al. identified that while only $9 \%$ of pregnant Canadian women used HNPs, $69 \%$ of these consumed at least one prescribed medicine [38]. Their study noted potential herb-drug interactions for more than a third of drug-herb combinations of which more than 1:4 had the potential to lead to serious adverse effects. In our study we identified that approximately $45 \%$ of women who reported herbal and natural product use also used prescription medicines, however we observed only one potentially serious interaction. The reasons for the lower prevalence of interactions, especially severe interactions, in our study population is not clear, however it is likely due to differences in the herbal and natural products used by the two study populations.

In our study four herbal and natural products, ginger, chamomile, grapefruit and fish oil, which are frequently used for the treatment of pregnancy related issues, accounted for $82 \%$ of all potential interactions. Moussally et al., however, reported that green tea, which did not appear in the top 10 herbs used by our cohort, accounted for 30\% of all herbdrug interactions in a Canadian population [38]. Although we have identified potential rather than actual interactions, these interactions may give rise to clinically significant adverse events, especially during labour and birth. Such herbdrug interactions have been previously reported to give rise to increased risk of bleeding, alteration of maternal haemodynamics and increased risk of central nervous system depression both maternal and fetal/neonatal [45-47]. Herbal supplements such as valerian, kava and chamomile when administered with opiate analgesics, which were the second largest prescribed drug group in our study cohort, may lead to increased central nervous system depression. Similarly, NSAIDs, particularly aspirin, have the potential to interact with herbal supplements which also possess antiplatelet activity, such as ginkgo, garlic, ginger, and ginseng, or with herbs containing coumarin such as chamomile, fenugreek and red clover, to enhance the risk of bleeding. We did not look specifically at the use of over the counter medicines (OTC), however in this study 11 women were prescribed paracetamol, a medicine which is commonly bought over the counter in pharmacies or supermarkets. The true use of paracetamol in our study population is therefore likely to have been significantly greater than reported. While many of the public regard paracetamol as a mild analgesic it does have the potential to interact with a number of herbs and food supplements such as Echinacea to increase the risk of bleeding, hepatotoxicity and nephrotoxicity.

\section{Strengths and limitations}

Respondents were provided with detailed checklists for specific herbal and natural products to ensure correct reporting of use. We have demonstrated previously that using such a checklist, rather than an open question about herbal or natural product use, produces a ninefold increase in the number of respondents who report herbal or food supplement use [44].

A limitation of our study however is the use of selfreported data and sampling from one centre, which may possibly limit generalizability, however the demographic makeup of our respondents is identical to that of the total pregnant population of England and Wales [48] indicating that our results are likely to be generalisable to the UK. To ensure an optimal response rate the questionnaire did not ask about the quantity, timing, dose or duration of herb and food supplements therefore it is 


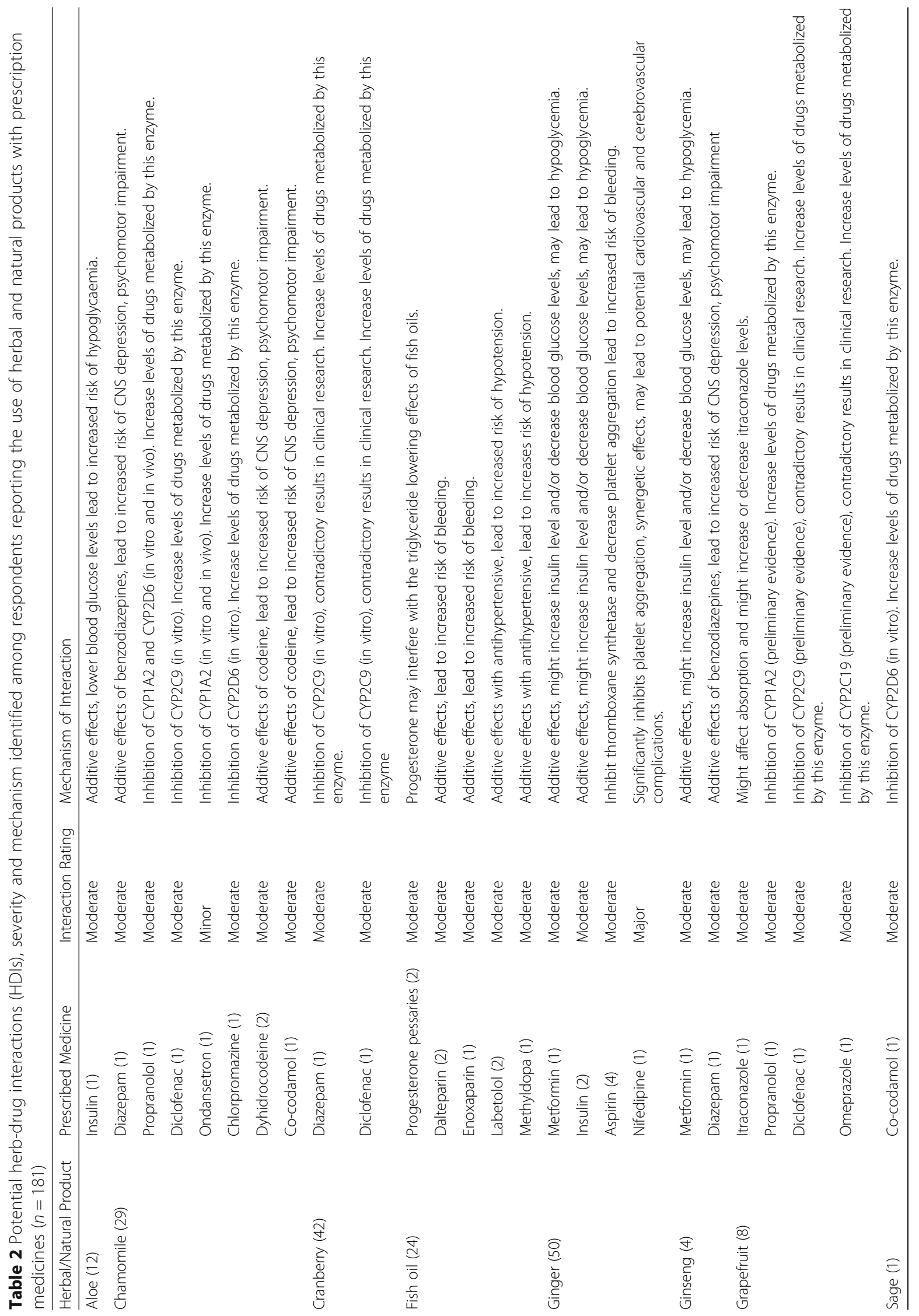


possible that women stopped taking their herbal medicines when prescribed an interacting medicine. Furthermore we did not collect data on medicines purchased over the counter (e.g. paracetamol), which may have led to an underestimation of the number of potential herbdrug interactions. Although we used a comprehensive international information source to identify potential interactions, it is possible that further interactions may have been identified had other information sources been used or that further herb-herb or herb-drug interaction are as yet unrecognised or unreported.

\section{Conclusion}

In the UK, HNPs are used by almost half of pregnant women, although most are unaware that they are using herbal medicines. While HNPs are often promoted as harmless and users may believe that HNPs provide a safe alternatives to pharmaceutical medicines, many HNPs contain active ingredients, which have the potential to interact with prescribed medication either directly or via modification of metabolism. In our study almost half of pregnant women were using prescribed medicines, excluding vitamins and minerals, and almost half of these also used HNPs. Because of the large number of HNPs available to the public it is not surprising that the toxicology for many is limited, however despite this we identified potential herb-drug interactions of moderate severity in approximately one in eight pregnant women using HNPs. While we were able to identify potential HDIs we were unable to determine whether individuals were affected clinically, however as there are approximately 700,000 births in the UK annually and approximately one fifth of these women use prescription and herbal medicines concurrently the number affected by HDIs is not insignificant. Healthcare professionals and those recommending HNPs should be aware that the concurrent use of HNPs and prescription medicines during pregnancy is common and may place the mother and fetus at potential risk.

\section{Abbreviations}

CAM: Complementary and Alterative Medicine; CNS: Central Nervous System; HDI: Herbal Drug Interaction; HNP: Herbal and Natural Product; NSAID: NonSteroid Anti-Inflammatory Drug; UK: United Kingdom; USA: United States

\section{Acknowledgements}

Not applicable

\section{Declaration of transparency}

JSM affirms that the manuscript is an honest, accurate, and transparent account of the study being reported; that no important aspects of the study have been omitted; and that any discrepancies from the study as planned have been explained.

\section{Funding}

All funding was from institutional resource. JSM, AS are employed by the University of Aberdeen. DS is employed by the Robert Gordon University. BP and $\mathrm{CR}$ are employed by NHS Scotland. ARP and MAH are employed by the Hamad Medical Corporation. Qatar. NI is a postgraduate student at the University of Aberdeen.
Availability of data and materials

All data generated or analysed during this study are included in this published article.

\section{Authors' contributions}

JSM (Principal Investigator), NI, ARP, AS, BP, CR, MAH, DS were involved with study design, data collection and analysis, and approving the final manuscript for submission.

\section{Ethics approval and consent to participate}

This research was approved by National Health Service North of Scotland Research Ethics Committee and National Health Service Grampian Research and Development Committee on June 27, 2011 (REC 11/ AL/0094). As the Ethics Committee required the survey questionnaires to be fully anonymous and returned directly by respondents in post-paid envelopes with no record of identifiable data, written consent to participate was deemed unnecessary.

Consent for publication

Not applicable

\section{Competing interests}

The authors declare that they have no competing interests.

\section{Publisher's Note}

Springer Nature remains neutral with regard to jurisdictional claims in published maps and institutional affiliations.

\section{Author details}

${ }^{1}$ The Division of Applied Health Sciences, The University of Aberdeen, Aberdeen, UK. ${ }^{2}$ Pharmacy Department, Women's Hospital-HMC, Doha, Qatar. ${ }^{3}$ The Department of Obstetrics and Gynaecology, The University of Aberdeen, Aberdeen, UK. ${ }^{4}$ The Department of Obstetrics and Gynaecology, Ninewells Hospital and Medical School, NHS Tayside, Dundee, UK. ${ }^{5}$ The Department of Pharmacy, Aberdeen Royal Infirmary, Aberdeen, UK. ${ }^{6}$ School of Pharmacy and Life Sciences. Robert Gordon University, Aberdeen, UK.

Received: 27 February 2017 Accepted: 7 December 2017

Published online: 19 December 2017

\section{References}

1. Posadzki P, Watson LK, Alotaibi A, Ernst E. Prevalence of use of complementary and alternative medicine (CAM) by patients/consumers in the UK: systematic review of surveys. Clin Med. 2013;13(2):126-31.

2. Barnes PM, Bloom B, Nahin RL. Complementary and alternative medicine use among adults and children: United States, 2007. Natl Health Stat Report; Hyattsville, MD: 2008. Natl Health Stat Report; no 12.

3. Clarke TC, Black LI, Stussman BJ, Barnes PM, Nahin RL. Trends in the use of complementary health approaches among adults: United States, 2002-2012. Natl Health Stat Report. 2015;10(79):1.

4. AARP NCCAM. Complementary and alternative medicine: what people aged 50 and older discuss with their health care providers. Consumer Survey Report. 2011, pp. 1-14

5. Eardley S, Bishop FL, Prescott P, Cardini F, Brinkhaus B, Santos-Rey K, et al. A systematic literature review of complementary and alternative medicine prevalence in EU. Forsch Komplementmed. 2012;19(Suppl 2):18-28.

6. Pallivalapila AR, Stewart D, Shetty A, Pande B, McLay JS. Complementary and alternative medicines use during pregnancy: a systematic review of pregnant women and healthcare professional views and experiences. Evid Based Complement Alternat Med. 2013 Sep:30:2013.

7. Ernst E. Herbal medicinal products during pregnancy: are they safe? BJOG. 2002;109:227-35.

8. Chuang CH, Doyle P, Wang JD, Chang PJ, Lai JN, Chen PC. Herbal medicines used during the first trimester and major congenital malformations an analysis of data from a pregnancy cohort study. Drug Saf. 2006;29:537-48.

9. Elvin-Lewis M. Should we be concerned about herbal remedies. J Ethnopharmacol. 2001;75:141-64.

10. Dugoua JJ, Mills E, Perri D, Koren G. Safety and efficacy of ginkgo (Ginkgo Biloba) during pregnancy and lactation. Can J Clin Pharmacol. 2006;13: e277-84.

11. Vickers A, Zollman CABC. Of complementary medicine: herbal medicine. BMJ. 1999;319:1050-3. 
12. Ko RJ. Adulterants in Asian patent medicines. N Engl J Med. 1998;399:847.

13. Briggs $G G$, Roger KF, Sumner JY. Drugs in pregnancy and lactation: a reference guide to fetal and neonatal risk. Philadelphia (PA): Lippincott Williams \& Wilkins; 2012

14. Moussally K, Bérard A. Exposure to herbal products during pregnancy risk preterm birth. Eur J Obstet Gynecol Reprod Biol. 2010;150:107-8.

15. Cuzzolin L, Francini-Pesenti F, Verlato G, Joppi M, Baldelli P, Benoni G. Use of herbal products among 392 Italian pregnant women: focus on pregnancy outcome. Pharmacoepidem Dr S. 2010;19:1151-8.

16. Steel A, Adams J, Sibbritt D, Broom A, Frawley J, Gallois C. Relationship between complementary and alternative medicine use and incidence of adverse birth outcomes: an examination of a nationally representative sample of 1835 Australian women. Midwifery. 2014 Dec 31;30(12):1157-65.

17. Facchinetti F, Pedrielli G, Benoni G, Joppi M, Verlato G, Dante G, et al. Herbal supplements in pregnancy: unexpected results from a multicentre study. Hum Reprod. 2012;27:3161-7.

18. Boivin J, Schmidt L. Use of complementary and alternative medicines associated with a 30\% lower on going pregnancy/live birth rate during 12 months of fertility treatment. Hum Reprod. 2009;24:1626-31.

19. Graham RE, Ahn AC, Davis RB, O'Connor BB, Eisenberg DM, Phillips RS. Use of complementary and alternative medical therapies among racial and ethnic minority adults: results from the 2002 National Health Interview Survey. J Natl Med Assoc. 2005;97:535-45.

20. Hunt KJ, Coelho HF, Wider B, Perry R, Hung SK, Terry R, et al. Complementary and alternative medicine use in England: results from a national survey. Int J Clin Pract. 2010;64(11):1496-502.

21. Kennedy DA, Lupattelli A, Koren G, Nordeng $\mathrm{H}$. Herbal medicine use in pregnancy: results of a multinational study. BMC Complement Altern Med. 2013;13:355.

22. Holst $L$, Norderg $H$, Haavik $S$. Use of herbal drugs during early pregnancy in relation to maternal characteristics and pregnancy outcome. Pharmacoepidem Dr S. 2008;17:151-9.

23. Adams J, Lui CW, Sibbritt D, Broom A, Wardle J, Homer C, et al. Women's use of complementary and alternative medicine during pregnancy: a critical review of the literature. Birth. 2009;36(3):237-45.

24. Fugh-Berman A, Kronenberg F. Complementary and alternative medicine (CAM) in reproductive-age women: a review of randomized controlled trials. Reprod Toxicol. 2003;17(2):137-52.

25. Hall HG, McKenna LG, Griffiths DL. Midwives' support for complementary and alternative medicine: a literature review. Women Birth. 2012;25(1):4-12.

26. Pallivalapilla AR, Stewart D, Shetty A, Pande B, Singh R, McLay JS. Complementary and alternative medicine use during early pregnancy. Eur J Obstet Gynecol Reprod Biol. 2014;181:251-5.

27. Pallivalapilla AR, Stewart D, Shetty A, Pande B, Singh R, McLay JS. Use of complementary and alternative medicines during the third trimester. Obstet Gynecol. 2015;125(1):204-11.

28. Forster DA, Denning A, Wills G, Bolger M. McCarthy. Herbal medicine use during pregnancy in a group of Australian women. BMC Pregnancy Childbirth. 2006;6:21.

29. Westfall RE. Herbal medicine in pregnancy and childbirth. Adv Ther. 2001;18(1):47-55

30. Nordeng H, Havnen GC. Use of herbal drugs in pregnancy: a survey among 400 Norwegian women. Pharmacoepidem Dr S. 2004;13(6):371-80.

31. Mitchell AA, Gilboa SM, Werler MM, Kelley KE, Louik C, Hernández-Díaz S, et al. Medication use during pregnancy, with particular focus on prescription drugs: 1976-2008. Am J Obstet Gynecol. 2011;205(1):51-e1.

32. Lupattelli A, Spigset O, Twigg MJ, Zagorodnikova K, Mårdby AC, Moretti ME, et al. Medication use in pregnancy: a cross-sectional, multinational webbased study. BMJ Open. 2014;4(2):e004365.

33. Stephansson O, Granath F, Svensson T, Haglund B, Ekbom A, Kieler H. Drug use during pregnancy in Sweden-assessed by the prescribed drug register and the medical birth register. Clinical Epidemiol. 2011;3:45-50.

34. Daw JR, Hanley GE, Greyson DL, Morgan SG. Prescription drug use during pregnancy in developed countries: a systematic review. Pharmacoepidem Dr S. 2011;20:895-902.

35. Lee E, Maneno MK, Smith L, Weiss SR, Zuckerman $1 H$, Wutoh AK, et al. National patterns of medication use during pregnancy. Pharmacoepidem Dr S. 2006; 1; 15(8):537-545.

36. Palmer ME, Haller C, McKinney PE, Klein-Schwartz W, Tschirgi A, Smolinske SC, et al. Adverse events associated with dietary supplements: an observational study. Lancet. 2003;361:101-6.
37. Izzo AA, Ernst E. Interactions between herbal medicines and prescribed drugs: an updated systematic review. Drugs. 2009;69(13):1777-98.

38. Moussally K, Oraichi D, Bérard A. Herbal products use during pregnancy: prevalence and predictors. Pharmacoepidem Dr S. 2009;18(6):454-61.

39. Mothupi MC. Use of herbal medicine during pregnancy among women with access to public healthcare in Nairobi, Kenya: a cross-sectional survey. BMC Complement Altern Med. 2014;14:432.

40. Nordeng H, Bayne K, Havnen GC, Paulsen BS. Use of herbal drugs during pregnancy among 600 Norwegian women in relation to concurrent use of conventional drugs and pregnancy outcome. Complement Ther Clin Prac. 2011;17(3):147-51

41. Tabatabaee M. Use of herbal medicine among pregnant women referring to Valiasr hospital in Kazeroon, Fars, south of Iran. J med. Plants. 2011;10(37): 96-108.

42. The Natural Medicines Comprehensive Database. http://naturaldatabase. therapeuticresearch.com/home.asp. Accessed 10/2016.

43. Robinson MM, Zhang X. Traditional medicines: global situation, issues and challenges. The World Medicines Situation. 2011 (3rd ed). WHO Geneva, 1-14.

44. Pallivalapila AR, Stewart D, Shetty A, Pande B, Al Hail M, McLay JS. Asking the right question. A comparison of two approaches to gathering data on 'Herbals' use in survey based studies. PLoS One. doi:10.1371/journal.pone. 0150140.

45. Kuczkowski KM. Labor analgesia for the parturient with herbal medicines use: what does an obstetrician need to know? Arch Gynecol Obstet. 2006; 274(4):233-9.

46. Abebe W. Herbal medication: potential for adverse interactions with analgesic drugs. J Clin Pharm Ther. 2002;27(6):391-401.

47. Smeriglio A, Tomaino A, Trombetta D. Herbal products in pregnancy: experimental studies and clinical reports. Phytother Res. 2014;28(8):1107-16.

48. Henderson J, Gao H, Redshaw M. Experiencing maternity care: the care received and perceptions of women from different ethnic groups. BMC Pregnancy Childbirth. 2013;13:196.

\section{Submit your next manuscript to BioMed Central and we will help you at every step:}

- We accept pre-submission inquiries

- Our selector tool helps you to find the most relevant journal

- We provide round the clock customer support

- Convenient online submission

- Thorough peer review

- Inclusion in PubMed and all major indexing services

- Maximum visibility for your research

Submit your manuscript at www.biomedcentral.com/submit
) Biomed Central 